\title{
The Mediterranean diet: does it have to cost more?
}

\author{
Adam Drewnowski ${ }^{1, *}$ and Petra Eichelsdoerfer ${ }^{2}$ \\ ${ }^{1}$ Nutritional Sciences Program and the Center for Obesity Research, School of Public Health and Community \\ Medicine, University of Washington, Seattle, WA 98195, USA: ${ }^{2}$ The Bastyr University Research Center, \\ Bastyr University, Kenmore, WA, USA
}

\section{Submitted July 2008: Accepted April 2009}

\begin{abstract}
Objective: To test the viability of the Mediterranean diet as an affordable low-energy-density model for dietary change.

Design: Foods characteristic of the Mediterranean diet were identified using previously published criteria. For these foods, energy density $(\mathrm{kJ} / 100 \mathrm{~g})$ and nutrient density in relation to both energy $(\$ / M J)$ and nutrient cost were examined.

Results: Some nutrient-rich low-energy-density foods associated with the Mediterranean diet were expensive, however, others that also fit within the Mediterranean dietary pattern were not.

Conclusions: The Mediterranean diet provides a socially acceptable framework for the inclusion of grains, pulses, legumes, nuts, vegetables and both fresh and dried fruit into a nutrient-rich everyday diet. The precise balance between good nutrition, affordability and acceptable social norms is an area that deserves further study. The new Mediterranean diet can be a valuable tool in helping to stem the global obesity epidemic.
\end{abstract}

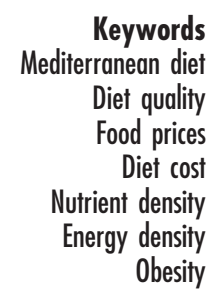

Rising rates of obesity worldwide have been linked to the growing consumption of energy-dense foods, many of which are increasingly nutrient poor ${ }^{(1)}$. Refined grains, added sugars and added fats have become the staple foods of industrialised nations ${ }^{(2)}$. Developing nations undergoing nutrition transition also replace the traditional plant-based diets with more simple sugars and more added fats ${ }^{(3)}$. Such energy-dense foods, high in fats, sugars and sodium, have the advantage of being good tasting, affordable and convenient. Providing dietary energy at very low cost, they are preferentially consumed by lower income groups. The new diets tend to be energy-dense, supplying more energy, but fewer nutrients per gram ${ }^{(4)}$.

The Mediterranean countries have not been spared by such dietary trends. Longitudinal analyses show that the diet of the Mediterranean nations has become much higher in both sugar and fat, and more homogeneous than it was in the $1960 \mathrm{~s}^{(5)}$. Children's body weight and health may have been adversely affected: data from IOTF (the International Obesity Taskforce) show that childhood obesity rates were higher in Mediterranean countries as compared to northern Europe ${ }^{(6)}$.

One might ask what happened to the Mediterranean diet and its protective effects on health. The traditional Mediterranean diet was rich in grains, plant foods and fish, with limited amounts of red meat. However, foods that were once inexpensive now cost much more. The Mediterranean diet has come to be viewed, at times, as a high-cost option for the elite, especially when transplanted from its rustic roots to an urban North American setting ${ }^{(7)}$. Yet, it might become a potential cultural model for low-energy-density diets everywhere.

The present analyses explored the interrelationships between energy density, nutrient density and the energy cost of foods and food groups said to be characteristic of the Mediterranean diet. The goal was to resolve a common dilemma. Foods with most nutrients and least energy tend to be the most expensive, at least on a per unit of energy (MJ, kcal) basis. As food prices rise (or the food budget shrinks), the first items dropped from the diet are the most costly and most healthful options: high-quality proteins, meat and fish, vegetables and fruit. Energy-dense refined grains, sugars and fat remain to fill hungry stomachs ${ }^{(8,9)}$.

Lower cost, yet nutritious options are rarely considered, partly because their use can violate social norms. With a few exceptions, pulses, legumes, nuts, dried fruit and canned fish are not a part of mainstream American diet. By contrast, they can be easily incorporated within a Mediterranean eating pattern. The Mediterranean diet provides a ready-made mechanism to include many such low-cost yet nutritious foods within a perfectly acceptable social and gastronomic framework. High-quality nutrition and high social acceptability might be the two advantages of the new Mediterranean diet.

\section{What is the Mediterranean diet?}

In 2003, Trichopoulou et al. described a diet scoring system that measured the degree of adherence to the 
traditional Mediterranean diet ${ }^{(10)}$. Based on dietary data collected using food frequency questionnaires, individual diets received one point if their consumption of specific foods or food groups was above the population median. No points were awarded if consumption fell below the median. Based on earlier research, the following foods, food groups and nutrients were said to be the essence of the traditional Mediterranean diet: vegetables (excluding potatoes), legumes, fruits, nuts and seeds, cereals, fish, ratio of PUFA to saturated fatty acids, and moderate alcohol consumption (in the 5-50 g range).

Similarly, foods considered detrimental to health were also scored according to whether the individual consumption was above ( 0 points) or below the median ( 1 point). Foods in the latter category included meat, poultry and dairy products. Finally, scores for beneficial and detrimental food classifications were added together for a final score, ranging from 0 to 9 . Higher scores, indicating higher adherence to a traditional Mediterranean diet, were associated with lower total mortality rates and with reduced death due to cancer or coronary heart disease ${ }^{(10-12)}$.

A few months later, Goulet et al. suggested a North American version of the Mediterranean diet ${ }^{(13)}$. The beneficial foods in the Mediterranean diet were identified as vegetables, legumes, fruits, nuts, whole-grain cereals, poultry, fish, canola and olive oils, and low-fat dairy products. Foods antithetical to the Mediterranean regime were identified as red meat, refined grains, sweets and desserts, fast foods and (whole/full fat) dairy products ${ }^{(13)}$. These principles are summarised in Table 1 below.

\section{Is the Mediterranean diet low-energy-density?}

Energy density of foods, defined as available joules (or calories) per unit weight ( $\mathrm{kJ} / 100 \mathrm{~g}$, or $\mathrm{kcal} / 100 \mathrm{~g})$, is largely a function of the foods' water content ${ }^{(14)}$. Because water provides weight but no energy, it contributes more to the energy density of foods than does any macronutrient, fat included. Together, water and fat account for over 95\% of the variance in the energy density of the food supply; sugars, starches and fibre play a relatively minor role.

Energy density of key foods and food groups in the Mediterranean diet was assessed using nutrient composition databases provided by the US Department of Agriculture (USDA). Figures 1 and 2 show an inverse relationship between the foods' water content and their energy density. Fruits and vegetables contain very high amounts of water $(\mathrm{w} / \mathrm{w})$; fruits generally contain $75-85 \mathrm{~g}$ of water per $100 \mathrm{~g}$ weight, whereas vegetables can contain as much as 85-95 $\mathrm{g}$ and have a slightly lower energy density compared to fruits. Dry grains and cereals were energy dense, whereas vegetables and fruit had energy density below $0 \cdot 21 \mathrm{MJ} / 100 \mathrm{~g} \quad(50 \mathrm{kcal} / 100 \mathrm{~g})$. Dried fruits contained $<30 \mathrm{~g}$ water per $100 \mathrm{~g}$ and had higher energy density. Beans and legumes were moderately high in water content $(65 \mathrm{~g} / 100 \mathrm{~g})$ and relatively low in energy density.

Yogurt and low-fat milk were low-energy-density foods containing 80-85 g water per $100 \mathrm{~g}$. Their energy density was in the range of $0 \cdot 3-0 \cdot 5 \mathrm{MJ} / 100 \mathrm{~g}(75-125 \mathrm{kcal} / 100 \mathrm{~g})$. Energy density of cheeses ( $40 \mathrm{~g}$ water/100 g), was $1 \cdot 5 \mathrm{MJ} /$ $100 \mathrm{~g}(350 \mathrm{kcal} / 100 \mathrm{~g})$. Energy density of fried fish (65-70\% water) was $1.7 \mathrm{MJ} / 100 \mathrm{~g}$ ( $400 \mathrm{kcal} / 100 \mathrm{~g})$.

Dry grains (5-15g water/100 g), and nuts and seeds $(<5 \mathrm{~g}$ water/100g) had higher energy density. Oils, including olive oil, had the highest energy density $(3 \cdot 8 \mathrm{MJ} / 100 \mathrm{~g}$, or $900 \mathrm{kcal} / 100 \mathrm{~g})$. The energy density of mixed dishes, such as pizza, stews or soups depended on their moisture and water content.

\section{Do Mediterranean foods cost more per $100 \mathrm{~g}$ ?}

Food-price data for the key foods in the Mediterranean diet were gathered in three principal Seattle supermarkets, in 2006. Exploring the relation between energy density and food cost per $100 \mathrm{~g}$ revealed a wide variation, both within and across food groups. For example, the price of fresh fruit varied widely from $\$ 0 \cdot 05-0 \cdot 10$ per $100 \mathrm{~g}$ to as much as $\$ 3 \cdot 00-5 \cdot 00$ per $100 \mathrm{~g}$. Most vegetables clustered around $\$ 0 \cdot 75 / 100 \mathrm{~g}$, although some fresh salad greens cost up to $\$ 2 \cdot 00$ or more per $100 \mathrm{~g}$.

The 2003 USDA report suggesting that Americans could obtain seven servings $(0.5$ cup or $50 \mathrm{~g}$ serving size) of fresh vegetables and fruit for as little as 64 cents seems to have little basis in reality ${ }^{(15)}$, unless the cheapest options were to be used exclusively every day. The USDA's 2005 My Pyramid avoided recommending numbers of servings daily in favour of recommending total volume consumption $^{(16)}$. However, if one applies their previous standard serving size to the 2005 recommendations (two servings of fruits and three servings of vegetables) ${ }^{(16)}$, daily costs could reach several dollars per day.

By contrast, legumes were low-energy-density and lowcost foods. Their cost per $100 \mathrm{~g}$ was generally between $\$ 0 \cdot 50-0 \cdot 75$, while their energy density ranged between $0 \cdot 4-0 \cdot 8 \mathrm{MJ} / 100 \mathrm{~g}(100-200 \mathrm{kcal} / 100 \mathrm{~g})$. Cereal prices clustered mostly between $\$ 0 \cdot 50-1 \cdot 00 / 100 \mathrm{~g}$, although some were very inexpensive $(\$ 0 \cdot 05 / 100 \mathrm{~g})$. Nuts and seeds had high energy density, around $2 \cdot 5 \mathrm{MJ} / 100 \mathrm{~g}$ (600 kcal/100 g), and cost approximately $\$ 1 \cdot 00 / 100 \mathrm{~g}$.

\section{Do Mediterranean foods cost more per $M J$ ?}

Budget constraints often determine diet composition, since some foods provide more energy per unit price than do other foods. Generally consumers need to obtain the daily energy ration of $8 \cdot 4-10 \cdot 5 \mathrm{MJ}(2000-2500 \mathrm{kcal} / \mathrm{d})$ at a given price. The Seattle food prices, initially calculated per $100 \mathrm{~g}$, were therefore adjusted for energy by dividing 
Table 1 Comparison of Mediterranean-diet scoring as described by Trichopoulou et al. and Goulet et al.

\begin{tabular}{|c|c|c|}
\hline Food group & $\begin{array}{l}\text { Greek Mediterranean diet score developed by } \\
\text { Trichopoulou et al. }{ }^{(10)}\end{array}$ & $\begin{array}{l}\text { Canadian Mediterranean diet score developed by } \\
\text { Goulet et al. }{ }^{(13)}\end{array}$ \\
\hline Vegetables & $\begin{array}{l}0=\text { intake less than median } \\
1=\text { intake greater than median } \\
\text { (Excluding potatoes) }\end{array}$ & $\begin{array}{l}0=\text { less than one serving daily } \\
1=\text { one serving daily } \\
2=\text { two servings daily } \\
3=\text { three servings daily } \\
4=\text { four or more servings daily }\end{array}$ \\
\hline Legumes & $\begin{array}{l}0=\text { intake less than median } \\
1=\text { intake greater than median }\end{array}$ & $\begin{array}{l}0=\text { less than } 0.5 \text { servings daily } \\
1=0.5 \text { servings daily } \\
2=\text { one serving daily } \\
3=\text { two servings daily } \\
4=\text { three or more servings daily }\end{array}$ \\
\hline Nuts and seeds & $\begin{array}{l}0=\text { intake less than median } \\
1=\text { intake greater than median }\end{array}$ & $\begin{array}{l}0=\text { less than } 0.5 \text { servings daily } \\
1=0.5 \text { servings daily } \\
2=\text { one serving daily } \\
3=\text { two servings daily } \\
4=\text { three or more servings daily }\end{array}$ \\
\hline Fruits & $\begin{array}{l}0=\text { intake less than median } \\
1=\text { intake greater than median }\end{array}$ & $\begin{array}{l}0=\text { less than one serving daily } \\
1=\text { one serving daily } \\
2=\text { two servings daily } \\
3=\text { three servings daily } \\
4=\text { four or more servings daily } \\
\text { (Maximum of } 1 \text { point for fruit juice) }\end{array}$ \\
\hline Cereals & $\begin{array}{l}0=\text { intake less than median } \\
1=\text { intake greater than median }\end{array}$ & $\begin{array}{l}0=\text { Less than one serving daily } \\
1=\text { one to two servings daily } \\
2=\text { three to four servings daily } \\
3=\text { five to six servings daily } \\
4=\text { seven or more servings daily } \\
\text { (Maximum of } 1 \text { point for refined grains) }\end{array}$ \\
\hline Fish & $\begin{array}{l}0=\text { intake less than median } \\
1=\text { intake greater than median }\end{array}$ & $\begin{array}{l}0=\text { none/never } \\
1=\text { less than one serving weekly } \\
2=\text { one serving weekly } \\
3=\text { two servings weekly } \\
4=\text { three or more servings weekly } \\
\text { (Non-breaded only) }\end{array}$ \\
\hline MUFA/Saturated fat ratio & $\begin{array}{l}0=\text { intake less than median } \\
1=\text { intake greater than median }\end{array}$ & \\
\hline Olive oil or olives & & $\begin{array}{l}0=\text { less than one serving daily } \\
1=\text { one serving daily } \\
2=\text { two servings daily } \\
3=\text { three servings daily } \\
4=\text { four or more servings daily }\end{array}$ \\
\hline $\begin{array}{l}\text { Canola oil or olive oil } \\
\text { margarine }\end{array}$ & & $\begin{array}{l}0=\text { Less than one serving daily } \\
1=\text { one or more servings daily }\end{array}$ \\
\hline Alcohol & $\begin{array}{l}0=\text { intake less than median } \\
1=\text { (men) intake } 10-50 \mathrm{~g} \text { daily } \\
1=\text { (women) intake } 5-25 \mathrm{~g} \text { daily }\end{array}$ & \\
\hline Meat & $\begin{array}{l}0=\text { intake greater than median } \\
1=\text { intake less than median }\end{array}$ & $\begin{array}{l}0=\text { seven or more servings weekly } \\
1=\text { five to six servings weekly } \\
2=\text { three to four servings weekly } \\
3=\text { one to two servings weekly } \\
4=\text { less than one serving weekly } \\
\text { (Red meats or processed meats) }\end{array}$ \\
\hline Poultry & $\begin{array}{l}0=\text { intake greater than median } \\
1=\text { intake less than median }\end{array}$ & $\begin{aligned} & 0= \text { none/never } \\
& 1=\text { one serving weekly, or four or more servings } \\
& \quad \text { weekly } \\
& 2= \text { two servings weekly } \\
& 3= \text { two servings weekly } \\
& 4= \text { three servings weekly } \\
& \text { (Non-breaded only) }\end{aligned}$ \\
\hline Dairy products & $\begin{array}{l}0=\text { intake greater than median } \\
1=\text { intake less than median }\end{array}$ & $\begin{array}{l}0=\text { Less than one serving daily, or more than } \\
\quad \text { four servings daily } \\
1=\text { four servings daily } \\
2=\text { not scored }\end{array}$ \\
\hline
\end{tabular}


Table 1 Continued

\begin{tabular}{|c|c|c|}
\hline Food group & $\begin{array}{c}\text { Greek Mediterranean diet score developed by } \\
\text { Trichopoulou et al. }{ }^{(10)}\end{array}$ & $\begin{array}{l}\text { Canadian Mediterranean diet score developed by } \\
\text { Goulet et al. }\end{array}$ \\
\hline & & $\begin{array}{l}3=\text { one serving daily } \\
4=\text { two to three servings daily }\end{array}$ \\
\hline Eggs & & $\begin{array}{l}0=\text { seven or more servings weekly } \\
1=\text { not scored } \\
2=\text { five to six servings weekly } \\
3=\text { not scored } \\
4=\text { zero to four servings weekly }\end{array}$ \\
\hline Sweets and desserts & & $\begin{array}{l}0=\text { seven or more servings weekly } \\
1=\text { five to six servings weekly } \\
2=\text { three to four servings weekly } \\
3=\text { one to two servings weekly } \\
4=\text { less than one serving weekly }\end{array}$ \\
\hline
\end{tabular}

MUFA, monounsaturated fatty acids.

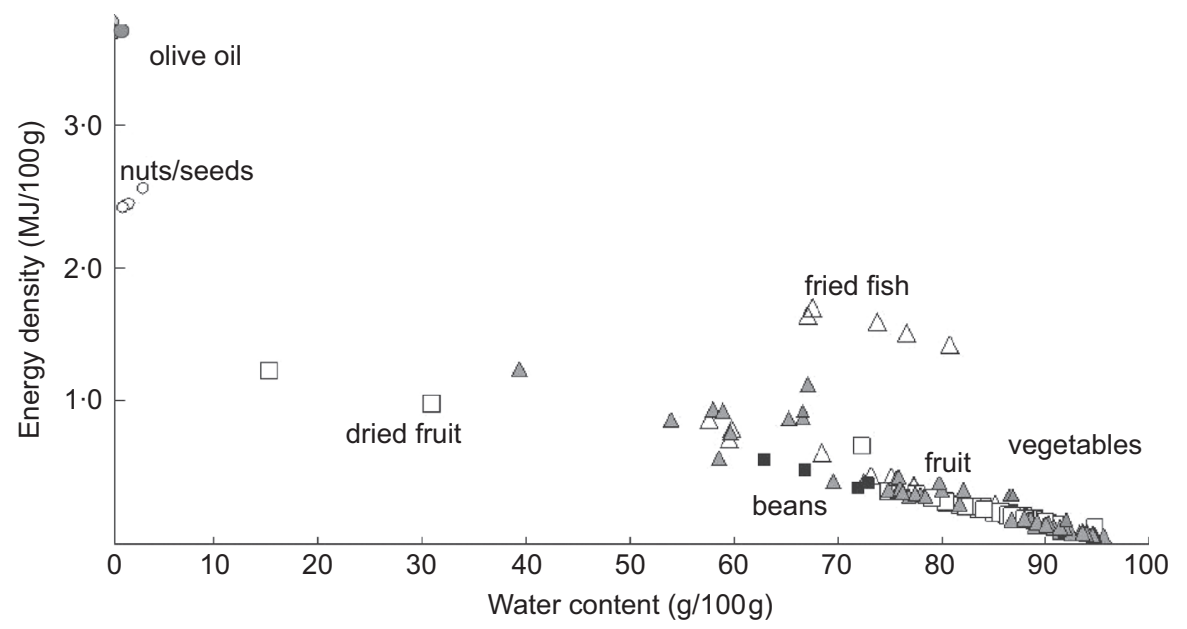

Fig. 1 The relation between energy density and water content in foods ( $\triangle$, fish; $\bigcirc$, fat/oil; o, nut/seed; $\square$, fruit; $\Delta$, vegetable; $\Delta$, alcohol; $\bullet$, legumes)

by the energy density of foods. Figure 3 shows energy density plotted against energy cost.

The low-energy-density fruits and vegetables, including berries, melons, salad and leafy greens, were associated with the highest per calorie energy costs. Meat, and especially fresh fish were relatively expensive, again on a per calorie basis. In contrast, dairy products, an alternative protein source, offered low energy density at moderate cost; most dairy products clustered around $0 \cdot 4 \mathrm{MJ} / 100 \mathrm{~g}$. The overall energy cost for dairy products tended to be lower than for meat or fish. Among vegetables, the less expensive root vegetables such as carrots or potatoes tended to be more energy dense. Legumes represent an important protein source, while offering relatively low energy density at a relatively low cost (\$1.00-25.00 per $4 \cdot 18 \mathrm{MJ}$, or $\$ 1 \cdot 00-25 \cdot 00$ per $1000 \mathrm{kcal}$ ).

Cereals generally cost less than meats, yet more than fats and oils. Their energy density varied roughly ten-fold, from $0 \cdot 2 \mathrm{MJ} / 100 \mathrm{~g}(50 \mathrm{kcal} / 100 \mathrm{~g})$ for oatmeal to $2 \cdot 0 \mathrm{MJ} /$ $100 \mathrm{~g}(500 \mathrm{kcal} / 100 \mathrm{~g})$ for granola bars with nuts and seeds. Generally, nuts and seeds cost between $\$ 1 \cdot 00-25 \cdot 00$ per $4 \cdot 18 \mathrm{MJ}(1000 \mathrm{kcal})$, in part due to their relatively high energy density.

Figure 4 reinforces the point that Mediterranean-style foods can be obtained at all price ranges, whether calculated per $100 \mathrm{~g}$ or per $4 \cdot 18 \mathrm{MJ}(1000 \mathrm{kcal})$. The only proviso is that the new Mediterranean diet needs to include more grains, legumes, nuts, vegetables and fruit, and less leafy greens and fresh fish. Doing so allows re-creation of the Mediterranean eating pattern at an affordable cost.

\section{Are Mediterranean foods nutrient-rich?}

The notion of dietary energy per unit cost needs to be supplemented with the notion of nutrients per unit cost. The question of whether Mediterranean foods are nutrient-rich can be answered using nutrient profiling, a quantitative method used to assess the nutrient quality of individual foods ${ }^{(17-19)}$. 


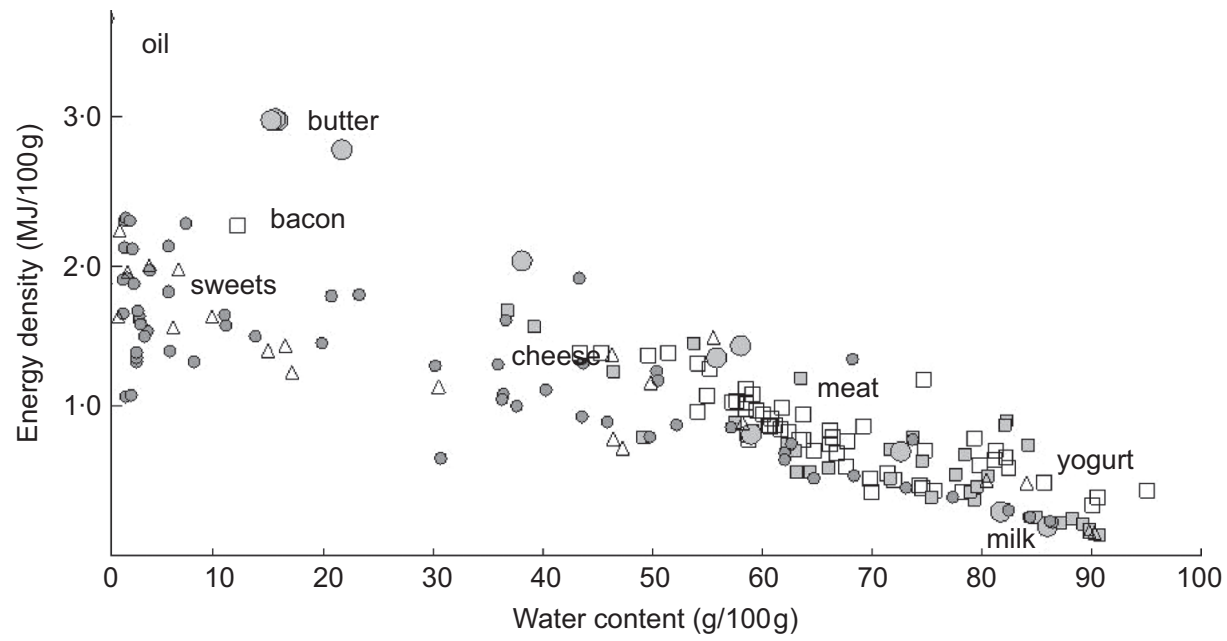

Fig. 2 The relation between energy density and water content in foods ( $\square$, meat; $\square$, dairy; $\bigcirc$, fat/oil; o, cereals; $\triangle$, sweets)

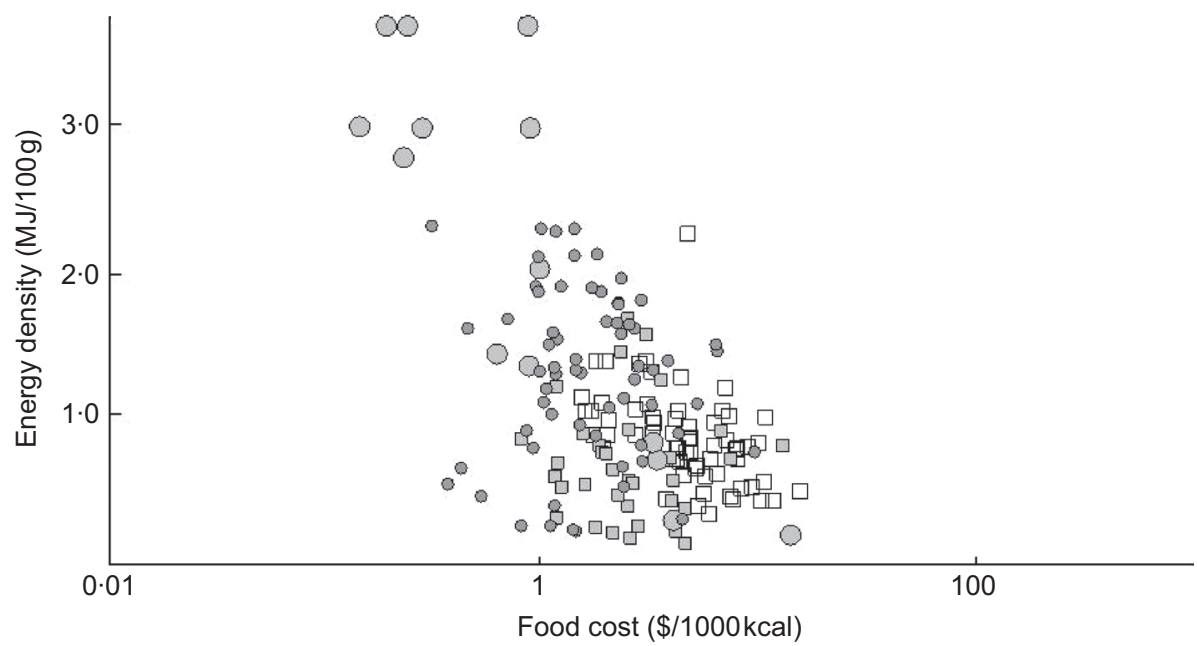

Fig. 3 The relation between energy density and food cost ( $\square$, meat; $\square$, dairy; $\bigcirc$, fat/oil; o, cereals)

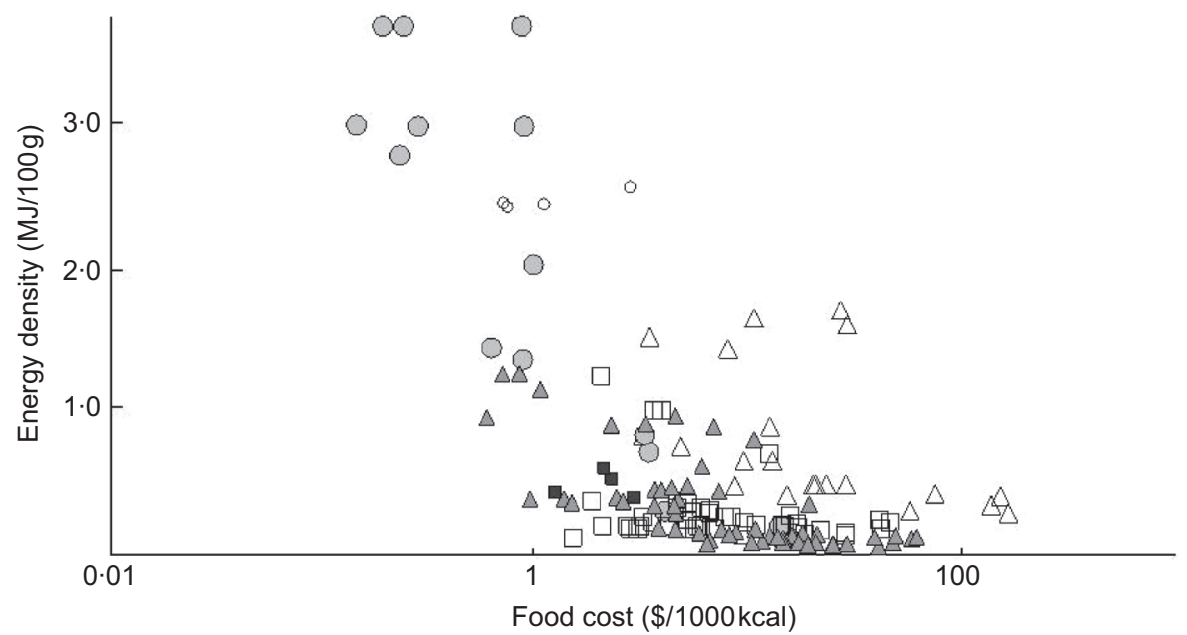

Fig. 4 The relation between energy density and food cost ( $\triangle$, fish; $\bigcirc$, fat/oil; o, nut/seed; $\square$, fruit; $\Delta$, vegetable; $\mathbf{m}$, legumes) 
Each food's nutrient adequacy score (NAS) can be calculated based on the nutrients the food contains relative to its provided dietary energy ${ }^{(9,17)}$. The NAS is based on percent daily value (DV) for $N$ key nutrients as provided by $100 \mathrm{~g}$ of food. Mathematically, this is represented as:

$$
\text { NAS }=\left(\Sigma\left(\text { Nutrient }_{\mathrm{i}} / \mathrm{DV}_{\mathrm{i}}\right) \times 100\right) / N .
$$

A food's nutrient density score (NDS) is based on percent DV as provided by $0 \cdot 4 \mathrm{MJ}(100 \mathrm{kcal})$ of food:

$$
\mathrm{NDS}=(\mathrm{NAS} / \mathrm{ED}) \times 100,
$$

where ED represents energy density. Finally, a nutrientto-price ratio (NPR) may be computed for each food using the expression:

$$
\mathrm{NPR}=\mathrm{NAS} / \text { price per } 100 \mathrm{~g} .
$$

The present analyses used the Naturally Nutrient Rich (NNR) index ${ }^{(17)}$ to assess the nutrient quality of individual foods typical of the Mediterranean diet. The NNR index was based on fifteen beneficial nutrients, including protein, fibre, monounsaturated fatty acids and a range of vitamins and minerals. Figures 5 and 6 show the relationship between NNR scores and the foods' energy density.

The low-energy-density foods were also most likely to be nutrient rich. Vegetables scored uniformly high. Most of the high-scoring vegetables had low energy densities. With the exception of dried fruit, the energy density of most fruit was low, with relatively high corresponding nutrient densities. Beans and legumes also had relatively high NNR scores.

Higher nutrient density scores were obtained for fish, both fresh and fried, organ meats and lean red meat than

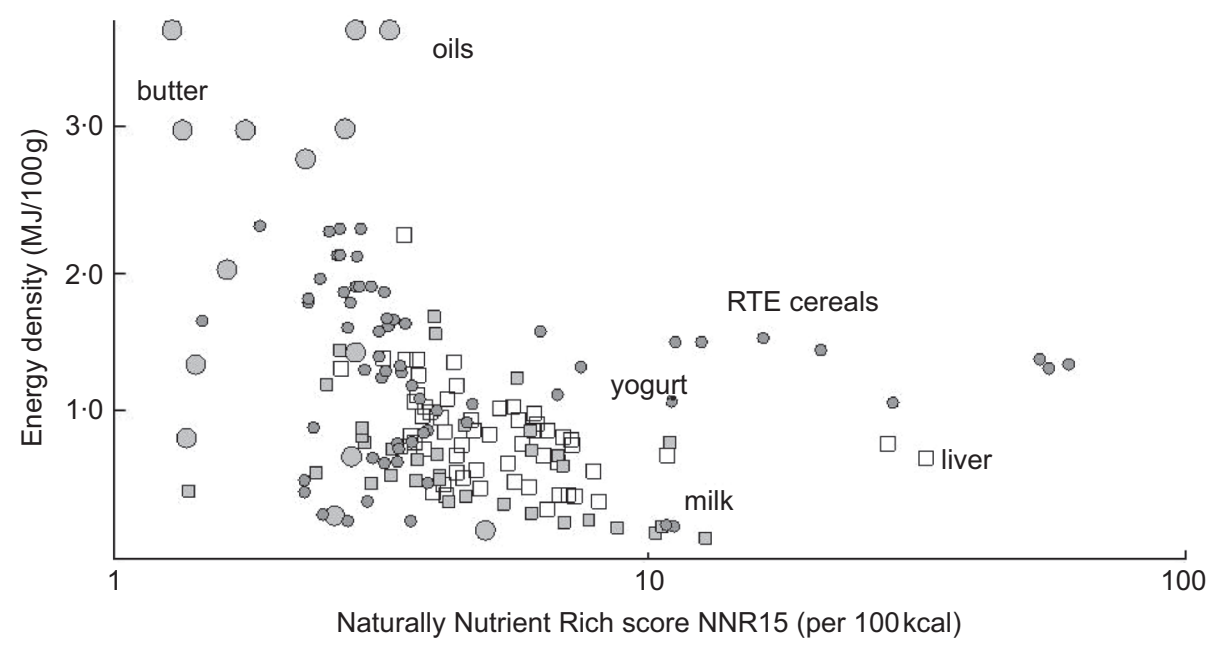

Fig. 5 The relation between energy density and nutrient density in foods ( $\square$, meat; $\square$, dairy; $\bigcirc$, fat/oil; o, cereals)

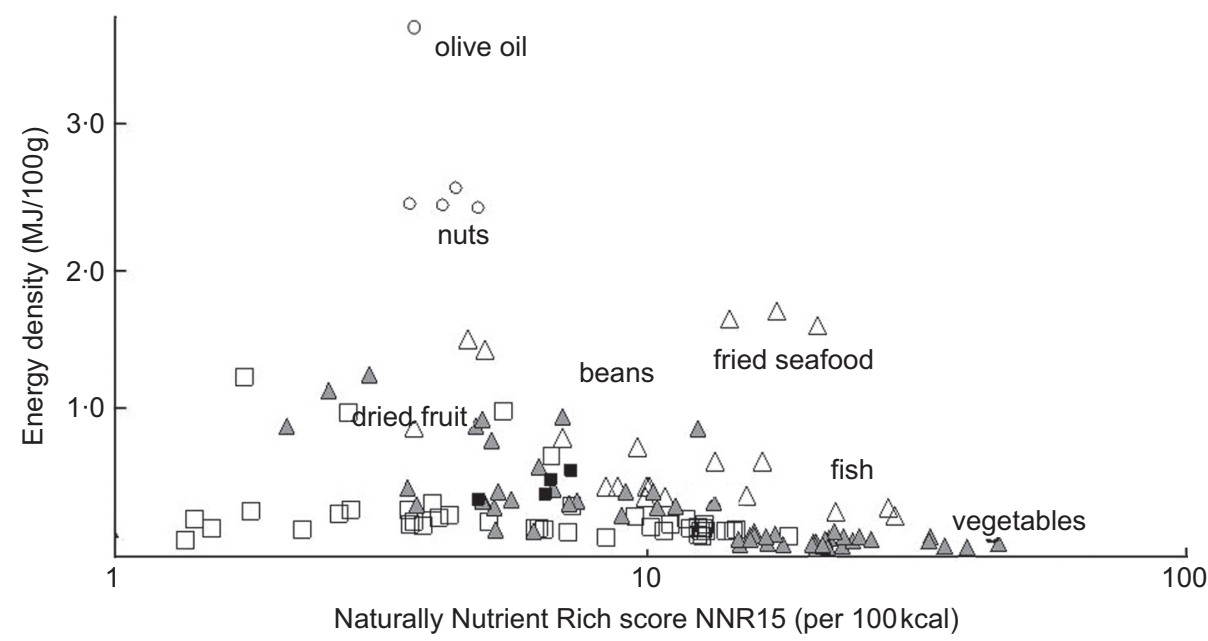

Fig. 6 The relation between energy density and nutrient density in foods ( $\triangle$, fish; o, nut/seed; $\square$, fruit; $\Delta$, vegetable; $\Delta$, alcohol; legumes) 
for processed meats and for high-fat cuts of meat. Dairy products showed a range of nutrient density scores, with highest scores obtained from low-fat yogurts and other low-fat dairy products. Some dry cheeses containing saturated fats and sodium tended to score less well. Additional NNR 15 scores are presented for cereals, nuts and seeds, oils and alcoholic beverages. Sweets and desserts represented poor nutritional value expressed as nutrients per unit cost.

As might be expected, given the inverse relation between energy density and energy cost, there was a positive relation between nutrient density and energy cost. However, not all nutrient-rich foods necessarily cost more. Among the more expensive foods were fish and shellfish, fruit, some vegetables, some cheeses and some nuts. Among the lower cost foods were other vegetables, beans and other legumes, grains, nuts and some dairy products. It should be possible to construct a Mediterranean-style diet using the lower cost options in every category.

\section{Can the Mediterranean diet halt the obesity epidemic?}

Diets high in refined grains, added sugars and added fats are both good tasting and affordable. Although inexpensive, such diets are energy dense and nutrient poor. The current emphasis is on replacing refined grains, fast foods, desserts, added sugars and added fats with more whole grains, lean meats, fish, and fresh vegetables and fruit. However, such diets, although palatable and nutritious, are usually associated with higher costs per MJ and per day.

Goulet et al. found that promoting a Mediterranean dietary pattern need not necessarily be associated with higher overall dietary costs ${ }^{(20)}$. The key to avoiding increased overall dietary costs lies in educating consumers about lower cost foods while selectively purchasing limited amounts of higher cost ones.

In controlled clinical trials, variations of the Mediterranean diet have demonstrated efficacy for both weight loss and improving glycaemic measures in diabetics. Shai et al. recently reported on a 2 -year intervention study in which those individuals assigned to an energy-restricted Mediterranean diet lost more weight initially and gained less back over time, in comparison to those assigned to an energy-restricted low-fat diet ${ }^{(21)}$. For female participants, the Mediterranean diet proved even more efficacious for weight loss. The diabetic subjects assigned to the Mediterranean-diet group experienced greater improvements in fasting plasma glucose and insulin ${ }^{(21)}$.

Attempts to steer Western consumers toward lower cost yet nutrient-dense foods have encountered resistance. Many diets composed of mostly plant foods with meat used only as a condiment, vegan-style diets, or diets based exclusively on rice and beans, are outside the

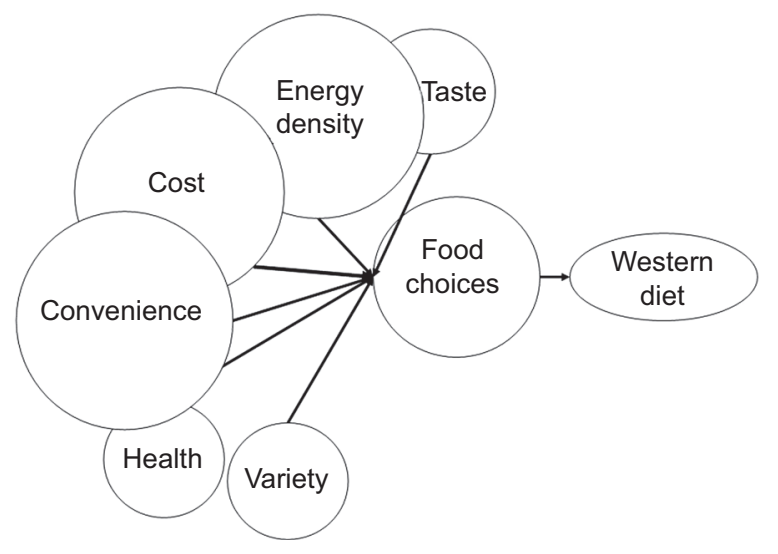

Fig. 7 The elements of consumer food choice

American or European mainstream. Consumers generally resist eating less-familiar foods, particularly if they believe that doing so means abandoning their cultural heritage, or that those foods are associated with people of different culture or different social class. People prefer eating within their own food culture, such that any recommended diet must meet the triple-test of nutrition, cost and social norms (see Fig. 7).

The multiple challenges involved in improving diet quality include helping people recognise the lower cost foods within their cultural heritage, reducing any stigma attached to (other) low-cost foods, increasing the convenience and accessibility of lower cost, lower energy density foods, and finally, doing so without sacrificing taste or enjoyment.

The barriers are not insurmountable. The Mediterranean diet, recently described as the cultural heritage of all mankind, offers a way to incorporate nutritious yet lower cost foods within a coherent gastronomic structure. Many cultures around the world feature plant-based dishes that include small amount of meats, and incorporate legumes, grains and other nutritious lower cost foods. The Mediterranean diet provides a viable cultural framework to incorporate low-cost yet nutritious foods into the diet, notably pasta and beans, vegetables (tomatoes, eggplant), oil, wine, dried fruit, nuts and seeds.

Allowing consumers to explore their shared cultural food heritage through culinary education might represent a first step. Adapting the traditional food preparation techniques to the modern world would help promote the Mediterranean diet. As with dried legumes, preparation techniques can facilitate convenience of preparing foods made using whole, unprocessed grains. Low- or non-fat dairy products and eggs represent less expensive protein sources. Fermented dairy products such as yogurt or kefir are traditional in the Mediterranean region. Pasta, grains and beans can help replace the more expensive meats and fresh fish. Mixed dishes featuring combinations of meat- and plant-based foods are one staple of the Mediterranean diet. Replacing added sugars and fats with dried 


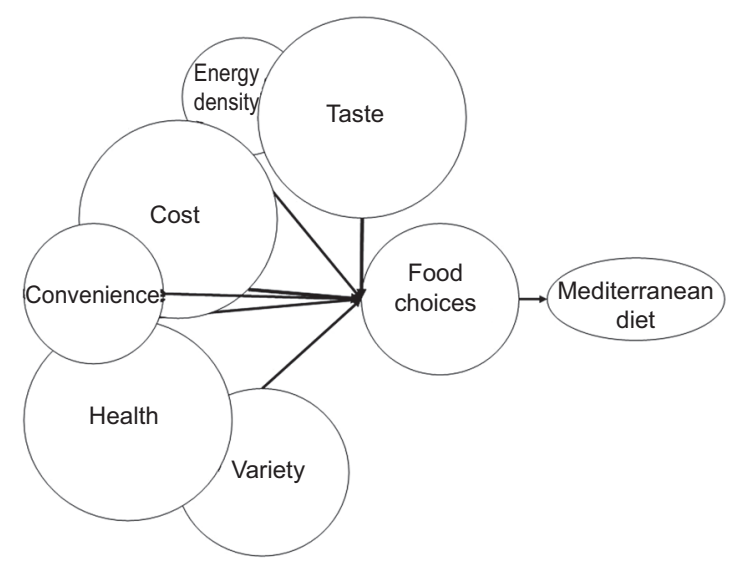

Fig. 8 The elements of consumer food choice

fruits, nuts and oils could enhance taste while providing increased nutrient value.

The combination of high enjoyment, low cost and good nutrition can be a powerful tool against the obesity epidemic (see Fig. 8). The Mediterranean diet, whether the traditional or the North American modified version, provides a social and gastronomic framework that need not be associated with higher diet costs.

\section{Acknowledgements}

A.D. was supported by USDA grant 2004-35215-1441 and P.E. was supported by NCCAM grant 2 T32AT000815. The authors' contributions were as follows: A.D. performed the data analysis, and both authors participated in writing the manuscript. There were no conflicts of interest.

\section{References}

1. World Health Organization (2003) Diet, Nutrition and the Prevention of Chronic Diseases. Joint WHO/FAO Expert Consultation. WHO Technical Report Series no. 916. Geneva: WHO; available at http://www.who.int/dietphysicalactivity/ publications/trs916/en/

2. Drewnowski A (2004) Obesity and the food environment: dietary energy density and diet costs. Am J Prev Med 27, 154-162.

3. Drewnowski A \& Popkin BM (1997) The nutrition transition: new trends in the global diet. Nutr Rev 55, 31-43.

4. Drewnowski A \& Darmon N (2005) The economics of obesity: dietary energy density and energy cost. Am J Clin Nutr 82, Suppl. 1, 265S-273S.
5. Schmidhuber J (2006) The changing structure of diets in the European Union in relation to healthy eating guidelines. Public Health Nutr 9, 584-595.

6. Lobstein T, Baur L \& Uauy R; IASO International Obesity TaskForce (2004) Obesity in children and young people: a crisis in public health. Obes Rev 5, Suppl. 4, 4-104.

7. Crotty P (1998) The Mediterranean diet as a food guide: the problem of culture and history. Nutr Today 33, 227-232.

8. Chan M (2008) Statement at the High-level Conference on World Food Security. Rome: WHO; available at http://www. fao.org/foodclimate/conference/statements/day1-pm/en/

9. Andrieu E, Darmon N \& Drewnowski A (2006) Low-cost diets: more energy, fewer nutrients. Eur J Clin Nutr 60, 434-436.

10. Trichopoulou A, Costacou T, Bamia C \& Trichopoulos D (2003) Adherence to a Mediterranean diet and survival in a Greek population. N Engl J Med 348, 2599-2608.

11. Mitrou PN, Kipnis V, Thiébaut ACM et al. (2007) Mediterranean dietary pattern and prediction of all-cause mortality in a US population. Arch Intern Med 167, 2461-2468.

12. Dai J, Miller AH, Bremner JD et al. (2008) Adherence to the Mediterranean diet is inversely associated with circulating interleukin-6 among middle-aged men: A twin study. Circulation 117, 169-175.

13. Goulet J, Lamarche B, Nadeau G \& Lemieux S (2003) Effect of a nutritional intervention promoting the Mediterranean food pattern on plasma lipids, lipoproteins and body weight in healthy French-Canadian women. Atherosclerosis 170, 115-124.

14. Drewnowski A (1998) Energy density, palatability, and satiety: implications for weight control. Nutr Rev 56, 347-353.

15. Reed J, Frazão E \& Itskowitz R (2004) How much do Americans pay for fruits and vegetables? United States Department of Agriculture, Agriculture information bulletin no. 790. http://www.ers.usda.gov

16. United States Department of Agriculture, Center for Nutrition Policy and Promotion (2005) Food Guide Pyramid: 'Inside the Pyramid'. http://www.mypyramid. gov/pyramid/index.html

17. Drewnowski A (2005) Concept of a nutritious food: toward a nutrient density score. Am J Clin Nutr 82, 721-732.

18. Maillot M, Darmon N, Darmon M, Lafay L \& Drewnowski A (2007) Nutrient-dense food groups have high energy costs: an econometric approach to nutrient profiling. J Nutr $\mathbf{1 3 7}$, $1815-1820$.

19. Drewnowski A, Monsivais P, Maillot M \& Darmon N (2007) Low-energy-density diets are associated with higher diet quality and higher diet costs in French adults. J Am Diet Assoc 107, 1028-1032.

20. Goulet J, Lamarche B \& Lemieux S (2008) A nutritional intervention promoting a Mediterranean food pattern does not affect total daily energy cost in North American women in free-living conditions. J Nutr 138, 54-59.

21. Shai I, Schwarzfuchs D, Henkin Y et al. (2008) Weight loss with a low-carbohydrate, Mediterranean, or low-fat diet. $N$ Engl J Med 359, 229-241. 